\title{
The association of MTHFR A1298C polymorphism with cervical cancer: An Updated Meta-Analysis Involving 2835 Subjects
}

\section{Chunyan Mu}

Xuzhou Medical University

\section{Zhongcheng Wang}

Xuzhou Medical University

\section{Yue Wang}

Xuzhou Medical University

Ying Li

Xuzhou Medical University

\section{Bing Gu}

Xuzhou Medical University

Ping Ma ( $\nabla$ pingm62@aliyun.com )

Xuzhou Medical University

Ting Lan ( $\nabla$ tina_8702@163.com )

Xuzhou Medical University https://orcid.org/0000-0001-7821-9537

\section{Research article}

Keywords: MTHFR, A1298C, polymorphism, cervical cancer

Posted Date: July 14th, 2020

DOI: https://doi.org/10.21203/rs.3.rs-32559/v1

License: (c) (1) This work is licensed under a Creative Commons Attribution 4.0 International License. Read Full License 


\section{Abstract}

Background Published data have reported the relationships between MTHFR A1298C polymorphisms and cervical cancer susceptibility. However, the conclusions of these findings lack consistency.

Methods A comprehensive literature search was performed using Web of Science, PubMed, EMBASE, Cochrane library, Wan Fang and CNKI databases. The pooled odds ratios (ORs) with $95 \%$ confidence intervals (Cls) were used to evaluate the correlation of MTHFR A1298C polymorphism and cervical cancer risk. Fixedeffects or random effects models was adopted according to heterogeneity test.

Results A total of nine studies ( 1145 cases and 1690 controls) were included in this meta-analysis. Pooled data revealed that MTHFR A1298C polymorphism was significantly associated with an increased risk of cervical cancer in the allele model $(P=0.028)$; the recessive model $(P=0.028)$; and the heterozygous model $(P=0.031)$.

Conclusions Our results revealed that MTHFR A1298C polymorphism was associated with risk of cervical cancer.

\section{Background}

Cervical cancer is a worldwide public health problem. In spite of being preventable, this disease is still the fourth most common type of cancer among women and the seventh among the general population [1]. Several certain factors appeared to be related with an increased risk of developing cervical cancer are early start of sexual life, multiple pregnancies, diet, smoking, and infection with human papilloma viruses (HPV), among which HPV infection was prominent [2, 3]. High-risk subtypes of the human papillomavirus (HPV) cause almost all cervix cancers [4]. However, this does not mean that all HPV infection ultimately cause cervix cancer. It was reported that a single same type HPV infection can only lead to cell immortalization and cannot induce malignant transformation of epithelial cells. HPV infection, with host internal and external environment factors, such as genetic polymorphism leading to susceptibility, the interaction of these factors causes an accumulation of cell damage that eventually leads to cancer.

Folic acid, as a water-soluble B vitamin [5], is essential for proper cellular function. Some studies have identified that levels of folate, play a role in cervical carcinogenesis [6, 7]. Folic acid is considered to be critical for the biosynthesis of purines and thymidylates which are key factors for normal DNA replication and repair as well as DNA methylation [8]. Once deficiency, it would impair cellular physiology and increase the risk of cervical cancer if it was accompanied by a persistent HPV infection. In addition to exogenous supplements, one of the most vital enzymes as intrinsic factor, named methylenetetrahydrofolate reductase (MTHFR), affect the level of folic acid. MTHFR catalyzes the conversion of 5,10-methylenetetrahydrofolate acid into 5methyltetrahydrofolate acid which is a major circulating form of folate acid. However, the activity of the enzyme was affected by gene polymorphism which was associated with reduced enzyme activity and folate deficiency [9]. There are 2 common types: one is a C-to-T transition at nucleotide 677 (677 C/T) in exon 4, resulting in an alanine-to-valine substitution that affects the catalytic domain of the enzyme, leading to reduced enzyme activity; another is an A-to-C transversion at position 1298 in exon 7 (1298A /C), resulting in 
a substitution of glutamate with alanine at codon 429 [10]. The later will also lead to low activity to a lesser extent, but the summary is lacking. Therefore, to address this gap, in this study, we assessed and explored the association between MTHFR 1298 A/C with the susceptibility of cervical cancer. Elucidation of an association, if any, might be informative regarding the hypothesis that impaired folate metabolism due to MTHFR polymorphism, resulting in low folate concentration, plays an intensified role in the occurrence of cervical cancer with HPV infection.

\section{Methods}

\section{Search strategy}

The meta-analysis was performed according to Preferred Reporting Items for Systematic Reviews and MetaAnalyses (PRISMA) guidelines [11]. Two authors independently searched electronic databases (Web of Science, PubMed, Embase, Cochrane library, WanFang and CNKI from inception to May 2019) for identify relevant articles. Electronic databases were searched using the keywords: "MTHFR", "A1298C", "rs1801131", "polymorphism", "SNP", "variant" and "cervical cancer". The reference lists of the retrieved articles were also searched carefully to identified other relevant publications.

\section{Inclusion and exclusion criteria}

Inclusion criteria: (1) case-control or cohort studies; (2) evaluated the association between MTHFR A1298C polymorphism and cervical cancer; (3) provided the sufficient data of allelic or genotypic frequencies of MTHFR A1298C; (4) the control group genotype followed Hardy-Weinberg equilibrium (HWE). Exclusion criteria: (1) reviews, duplication, case reports or animal studies; (2) incomplete data; (3) not case-control study.

\section{Data extraction}

Two authors independently extracted the necessary data from each eligible article, and disagreements were reconciled by third author. The following data form each study were extracted: first author's name, year of publication year, country, ethnicity of population, genotyping methods, number of cases and control, genotyping data, Hardy-Weinberg equilibrium (HWE) in controls.

\section{Quality assessment}

The Newcastle-Ottawa Quality Scale (NOS) was used by two authors to evaluate the quality of the studies [12].

\section{Statistical analysis}

All statistical analyses were performed Stata 12.0 software (StataCorp, College Station, TX, USA). Five allelic models as allelic model (A vs. C), heterozygote model (AA vs. AC), homozygote model (AA vs. CC), recessive ( $A A$ vs. $A C+C C$ ), and dominant (CC vs. AA+AC) model were used to estimate the association between MTHFR A1298C polymorphism and cervical cancer. HWE of the control populations was calculated with Chi-square test and the significance level was defined as $p<0.05$. The pooled ORs with $95 \%$ confidence intervals (Cls) 
were used to evaluate the correlation of MTHFR A1298C polymorphism and cervical cancer risk. P value < 0.05 was considered statistically significant. Heterogeneity across studies was assessed by the $Q$ and $I^{2}$ tests. If heterogeneity was detected $\left(P<0.05, I^{2}>50 \%\right)$, the random-effects model was be used to pool ORs. Otherwise, the fixed-effects model was adopted. Publication bias was assessed by Begg's funnel plots and Egger's regression test. The sensitivity analysis was performed to evaluate the stability of the pooled results. Subgroup analyses were performed according to the ethnicity.

\section{Results}

\section{Characteristics of Studies}

After initial search, a total of 132 articles were identified, of which 40 were excluded as duplicates. Of these, 62 records were excluded after screening titles and abstracts. 21 irrelevant studies were excluded after reading full papers. Ultimately, nine articles [13-21] were included in this meta-analysis according to inclusion criteria. The literature screening process was shown in Figure 1. Characteristics of the included studies in this meta-analysis are presented in Table 1. Among these studies, 6 studies were performed in Asian populations, 3 studies were conducted in Caucasian populations. The articles were published from 2006 to 2018 . Two case-control studies were deviated from the $\operatorname{HWE}[20,21]$.

\section{Quantitative Synthesis}

The results revealed that MTHFR A1298C polymorphism was significantly associated with cervical cancer susceptibility in the whole population under allelic (OR: 1.99, 95\% Cl: 1.08 3.67), recessive (OR: $0.48,95 \% \mathrm{Cl}$ : $0.25 \sim 0.92$ ) and heterozygous genetic models (OR: 1.75, 95\% Cl: 1.05 2.92). No significant association was found between them under dominant (OR: $2.91,95 \% \mathrm{Cl}: 0.93 \sim 9.12)$ and homozygous genetic models (OR: 3.76, 95\% Cl: 0.92 15.40) (Figures 2-6; Table 2). In the subgroup analysis by ethnicity, no significant results were found for Caucasian and Asian population under all five genetic models (Table 3 ). There was also significant heterogeneity under the all the genetic models. Meta-regression was performed to explore the source of heterogeneity under these genetic models. The confounding factors included the publication year, ethnicity. However, these confounding factors couldn't explain the heterogeneity $(P>0.05) \rrbracket$

\section{Sensitivity Analysis and Bias Diagnostics}

In the current meta-analysis, there was high heterogeneity under recessive, dominant, homozygous and allelic genetic models. Thus, sensitivity analysis was performed by removing one study and re-calculated the pooled ORs and Cls to evaluate stability of the result. After the Gong et al. was removed from the current metaanalysis, the heterogeneity was significance decreased while still providing results consistent with our initial findings (Figure 7). However, removal of any other studies did not change the results from the original analysis. Therefore, the study of Gong et al. was the high sensitivity study on the pooled OR. Begg's and Egger's test implied that there was no publication bias in the current analysis (Figure 8; Table 2)

\section{Discussion}


Infection by HPV is not exclusive to cause cervical cancer. Genetic polymorphism is also important in inducing cervicogenesis collectively. Moreover, in distinct populations, the relationship between the risk of cervical tumorigenesis and gene polymorphism was almost various. In our analysis, 1145 cases and 1690 controls from nine publications were involved. The meta-analysis results showed that MTHFR A1298C is a risk factor for cervical cancer, especially in Asian population. As to MTHFR A1298C polymorphism, in previous study, Zhuo et al. [22] published the first meta-analysis assess the association between MTHFR A1298C gene polymorphisms and cervical cancer risk and did not find significant associations. In contrast, recent meta-analysis by Yi et al. [23], including five studies, suggested that the significant associations between MTHFR A1298C polymorphism and cervical cancer were found among Asians. However, these studies were limited to small sample sizes and high heterogeneity. Therefore, we performed a comprehensive large-scale meta-analysis to investigate these associations. We performed a more comprehensive large-scale meta-analysis (nine studies involving 2835 individuals) to accurately assess these associations.

Folate was indicated a protective effect on cervical epithelial cell [24]. In addition, multiple clinical evidences have reported that evaluated level folate level was inversely related with the risk of cervical cancer $[19,25,26]$. As the introduction described, folate metabolism is very important for protection of cervical epithelial cell through maintain the methylation, repair, and synthesis of DNA [27]. In physically, folates appear to be essential for cell growth and cell cycle. Once folate deficiency induces lower proliferation rates by increased apoptosis and cell cycle arrest[28]. Thus, this is very negative for normal cell survival, which would promote cell transformation into cancer cells. Some study has shown that low level of serum folate may increase the risk of cervical cancer. Furthermore, it could be potential synergy with HPV infection, promoting cervical cancer development [29]. In our study, we set up the relation of MTHFR, as a key enzyme involving the chemical reaction of vitamin folate, A1298C polymorphism and cervical cancer susceptibility. It is this polymorphism that affects the activity of the enzyme and leads to low folate concentration in serum. To be more specific, the activity was decreased when a substitution of glutamate with alanine occurred.

In basic research, carriers of variant alleles for MTHFR1298 exhibit genome-wide DNA hypomethylation, which is a characteristic of genome instability [30]. When the activity of MTHFR was decreased or lose, it would lead to relaxation of heterochromatin, a decrease of H3K9me3 levels that often associates with heterochromatin at the centromeric and telomeric regions, and an increase of certain transcripts at the centromeric region. In summary, it would destroy heterochromatin or whole genome stability [31]. Thus, it was not hard to speculate the hazardous of MTHFR A1298C. It has reported that the MTHFR 1298C allele frequency is approximately $20-70 \%$ in Asia, $24-46 \%$ in Europe, and 0-15\% in America [32], which may explain why Asians are strong association. This could give us an appropriate reminder that Asians with carriers of variant alleles for MTHFR1298 may probably more likely to get cervical cancer, if they are infected HPV simultaneously.

In our study, there are still some limitations as follows. Firstly, the sample size was relatively small and may not have provided sufficient statistical power. More studies with a larger sample size are required. Meanwhile, it is hoped that the exploration was expanded on the association of MTHFR A1298C polymorphism and tumors of the female reproductive system, including ovarian cancer, which will make the study more broadspectrum and meaningful. Secondly, the subgroup analyses according to age, histological types and other 
elements were not performed owing to insufficient relevant data. Thus, it is suggested that future study could combine environmental factors, age and genetic polymorphism together to explore the interaction. Thirdly, given that the MTHFR has two types of polymorphisms, whether there is an interaction is unknown.

\section{Conclusions}

Our meta-analysis suggested that MTHFR A1298C was associated with cervical cancer development, especially in Asian population. In the future, well-designed and larger-scale studies are necessary to explore the roles of tumor stage, smoking, histology, or gene-gene/gene-environment interactions in the pathogenesis of cervical cancer.

\section{Abbreviations}

MTHFR: methylenetetrahydrofolate reductase; HPV: human papilloma viruses; $677 \mathrm{C} / \mathrm{T}$ : C-to-T transition at nucleotide 677; 1298A/C: A-to-C transversion at position 1298 in exon 7; PRISMA: Preferred Reporting Items for Systematic Reviews and Meta-Analyses; HWE: Hardy-Weinberg equilibrium; NOS: Newcastle-Ottawa Quality Scale; OR: odds ratio; Cl: confidence intervals.

\section{Declarations}

\section{Ethics approval and consent to participate}

Not applicable.

\section{Consent for publication}

Not applicable.

\section{Avaliability of date and meterials}

All data are included in this article.

\section{Competing interests}

The authors declare that they have no conflicts of interests.

\section{Funding}

This study was supported by the National Natural Science Foundation of China (Grant No. 81802063, 81802086, 81801168), the Natural Science Foundation of the Jiangsu Higher Education Institutions of China (Grant No. 18KJB320026), the Specialized Research Fund for Senior Personnel Program of Xuzhou medical University (Grant No. D2017022, D2016017), the Natural Science Foundation of Jiangsu Province (Grant No. BK20160228).

\section{Authors ' contributions}


TL and PM conceived and designed this study. CM and ZW collected literatures, extracted and analyzed the date and wrote this article. YW and YL took part in controversial articles selection. BG and TL participated in quality assessment. All authors read the manuscript and favored submission.

\section{Acknowledgements}

No applicable.

\section{References}

1. Ferlay J, Soerjomataram I, Ervik M, Dikshit R, Eser S, Al MCE. GLOBOCAN 2012 v1.0, Cancer incidence and mortality worldwide: IARC cancerbase. 2014.

2. Smith RA, Andrews KS, Brooks D, Fedewa SA, Manassaram-Baptiste D, Saslow D, Brawley OW, Wender RC. Cancer screening in the United States, 2017: A review of current American Cancer Society guidelines and current issues in cancer screening. CA Cancer J Clin 2017, 67(2):100-121.

3. Luhn P, Walker J, Schiffman M, Zuna RE, Dunn ST, Gold MA, Smith K, Mathews C, Allen RA, Zhang R et al. The role of co-factors in the progression from human papillomavirus infection to cervical cancer. Gynecol Oncol 2013, 128(2):265-270.

4. Crosbie EJ, Einstein MH, Franceschi S, Kitchener HC. Human papillomavirus and cervical cancer. Lancet 2013, 382(9895):889-899.

5. Duthie SJ. Folic acid deficiency and cancer: mechanisms of DNA instability. Br Med Bull 1999, 55(3):578592.

6. Tomita LY, D'Almeida V, Villa LL, Franco EL, Cardoso MA, Group BS. Polymorphisms in genes involved in folate metabolism modify the association of dietary and circulating folate and vitamin B- 6 with cervical neoplasia. The Journal of nutrition 2013, 143(12):2007-2014.

7. Asemi Z, Vahedpoor Z, Jamilian M, Bahmani F, Esmaillzadeh A. Effects of long-term folate supplementation on metabolic status and regression of cervical intraepithelial neoplasia: A randomized, double-blind, placebo-controlled trial. Nutrition (Burbank, Los Angeles County, Calif) 2016, 32(6):681-686.

8. Butterworth CE, Jr. Effect of folate on cervical cancer. Synergism among risk factors. Ann N Y Acad Sci 1992, 669:293-299.

9. Frosst P, Blom HJ, Milos R, Goyette P, Sheppard CA, Matthews RG, Boers GJ, den Heijer M, Kluijtmans LA, van den Heuvel LP et al. A candidate genetic risk factor for vascular disease: a common mutation in methylenetetrahydrofolate reductase. Nat Genet 1995, 10(1):111-113.

10. van der Put NM, Gabreels F, Stevens EM, Smeitink JA, Trijbels FJ, Eskes TK, van den Heuvel LP, Blom HJ. A second common mutation in the methylenetetrahydrofolate reductase gene: an additional risk factor for neural-tube defects? Am J Hum Genet 1998, 62(5):1044-1051.

11. Moher D, Liberati A, Tetzlaff J, Altman DG, Group P. Preferred reporting items for systematic reviews and meta-analyses: the PRISMA statement. PLoS Med 2009, 6(7):e1000097.

12. Stang A. Critical evaluation of the Newcastle-Ottawa scale for the assessment of the quality of nonrandomized studies in meta-analyses. Eur J Epidemiol 2010, 25(9):603-605. 
13. Delgado-Enciso I, Martinez-Garza SG, Rojas-Martinez A, Espinoza-Gomez F, Canseco-Avila LM, VidalGutierrez O, Garza-Leal JG, Barboza-Quintana O, Flores-Gutierrez JP, Barrera-Saldana HA et al. [The effect of MTHFR polymorphisms, pregnancy and first intercourse on cervical cancer in a population from the Northeastern Mexico]. Revista de investigacion clinica; organo del Hospital de Enfermedades de la Nutricion 2006, 58(5):462-469.

14. Fan YF, Li J, Xu RX, Yang F. Study on the relationship between the MTHFR polymorphism, the level of the folic acid and the cervical cancer susceptibility. . J Sichuan Univ (Med Sci Edi) 2014, 45(02):258-261.

15. Gong JM, Shen Y, Shan WW, He YX. The association between MTHFR polymorphism and cervical cancer. Sci Rep 2018, 8(1):7244.

16. Hajiesmaeil M, Tafvizi F, Sarmadi S. The effect of methylenetetrahydrofolate reductase polymorphisms on susceptibility to human papilloma virus infection and cervical cancer. Infection, genetics and evolution : journal of molecular epidemiology and evolutionary genetics in infectious diseases 2016, 46:1-6.

17. Kang S, Kim JW, Kang GH, Park NH, Song YS, Kang SB, Lee HP. Polymorphism in folate- and methioninemetabolizing enzyme and aberrant $\mathrm{CpG}$ island hypermethylation in uterine cervical cancer. Gynecol Oncol 2005, 96(1):173-180.

18. Kohaar I, Kumar J, Thakur N, Hussain S, Niyaz MK, Das BC, Sengupta S, Bharadwaj M. Homocysteine levels are associated with cervical cancer independent of methylene tetrahydrofolate reductase gene (MTHFR) polymorphisms in Indian population. Biomarkers 2010, 15(1):61-68.

19. Tong SY, Kim MK, Lee JK, Lee JM, Choi SW, Friso S, Song ES, Lee KB, Lee JP. Common polymorphisms in methylenetetrahydrofolate reductase gene are associated with risks of cervical intraepithelial neoplasia and cervical cancer in women with low serum folate and vitamin B12. Cancer causes \& control : CCC 2011, 22(1):63-72.

20. Xi BB. Analysis to Influence of MMPs and MTHFR Polymorphisms on Susceptibility of Cervical Cancer. \. Shandong University.; 2016.

21. Yang F, Zhou YL, Jiang Y, Fan YF, Li J. Study on the correlation between polymorphism of MTHFR gene and the pathogenesis of cervical cancer. Maternal \& Child Health Care of China 2011, 26(26):4087-4089.

22. Zhuo WL, Zhang L, Ling JJ, Zhu Y, Chen ZT. MTHFR C677T and A1298C polymorphisms and cervical carcinoma susceptibility: meta-analyses based on 4,421 individuals. Mol Biol Rep 2012, 39(9):87238732.

23. Yi K, Yang L, Lan Z, Xi M. The association between MTHFR polymorphisms and cervical cancer risk: a system review and meta analysis. Arch Gynecol Obstet 2016, 294(3):579-588.

24. Garcia-Closas R, Castellsague X, Bosch X, Gonzalez CA. The role of diet and nutrition in cervical carcinogenesis: a review of recent evidence. International journal of cancer 2005, 117(4):629-637.

25. Weinstein SJ, Ziegler RG, Selhub J, Fears TR, Strickler HD, Brinton LA, Hamman RF, Levine RS, Mallin K, Stolley PD. Elevated serum homocysteine levels and increased risk of invasive cervical cancer in US women. Cancer causes \& control : CCC 2001, 12(4):317-324.

26. Bai LX, Wang JT, Ding L, Jiang SW, Kang HJ, Gao CF, Chen X, Chen C, Zhou Q. Folate deficiency and FHIT hypermethylation and HPV 16 infection promote cervical cancerization. Asian Pac J Cancer Prev 2014, 
15(21):9313-9317.

27. Knock E, Deng L, Krupenko N, Mohan RD, Wu Q, Leclerc D, Gupta S, Elmore CL, Kruger W, Tini M et al. Susceptibility to intestinal tumorigenesis in folate-deficient mice may be influenced by variation in onecarbon metabolism and DNA repair. J Nutr Biochem 2011, 22(11):1022-1029.

28. Courtemanche C, Huang AC, Elson-Schwab I, Kerry N, Ng BY, Ames BN. Folate deficiency and ionizing radiation cause DNA breaks in primary human lymphocytes: a comparison. FASEB J 2004, 18(1):209211.

29. Zhao W, Hao M, Wang Y, Feng N, Wang Z, Wang W, Wang J, Ding L. Association between folate status and cervical intraepithelial neoplasia. Eur J Clin Nutr 2016, 70(7):837-842.

30. Castro R, Rivera I, Ravasco P, Camilo ME, Jakobs C, Blom HJ, de Almeida IT. 5,10methylenetetrahydrofolate reductase (MTHFR) 677C->T and 1298A->C mutations are associated with DNA hypomethylation. J Med Genet 2004, 41(6):454-458.

31. Zhu B, Xiahou Z, Zhao H, Peng B, Zhao H, Xu X. MTHFR promotes heterochromatin maintenance. Biochem Biophys Res Commun 2014, 447(4):702-706.

32. Yang B, Liu Y, Li Y, Fan S, Zhi X, Lu X, Wang D, Zheng Q, Wang Y, Wang Y et al. Geographical distribution of MTHFR C677T, A1298C and MTRR A66G gene polymorphisms in China: findings from 15357 adults of Han nationality. PLoS One 2013, 8(3):e57917.

\section{Tables}

Table 1. Characteristics of the investigated studies of the association between the MTHFR A1298C polymorphism and cervical cancer.

\begin{tabular}{|c|c|c|c|c|c|c|c|c|c|c|c|c|c|}
\hline \multirow[t]{2}{*}{ First author } & \multirow[t]{2}{*}{ Year } & \multirow[t]{2}{*}{ Country } & \multirow[t]{2}{*}{ Ethnicity } & \multirow{2}{*}{$\begin{array}{l}\text { Genotyping } \\
\text { method }\end{array}$} & \multirow{2}{*}{$\begin{array}{l}\text { Sample size } \\
\text { (cases/controls) }\end{array}$} & \multicolumn{3}{|c|}{ Case } & \multicolumn{3}{|c|}{ Controls } & \multirow{2}{*}{$\begin{array}{c}\text { HWE } \\
\text { (control) }\end{array}$} & \multirow{2}{*}{$\begin{array}{l}\text { Quality } \\
\text { score }\end{array}$} \\
\hline & & & & & & $\mathbf{A A}$ & $\mathrm{AC}$ & $\mathrm{CC}$ & $\mathbf{A A}$ & $\mathrm{AC}$ & $\mathrm{CC}$ & & \\
\hline Kang & 2005 & Korea & Asian & PCR-RFLP & $79 / 84$ & 55 & 22 & 2 & 58 & 25 & 1 & 0.344 & 7 \\
\hline Tong & 2011 & Korea & Asian & Taqman & $148 / 428$ & 89 & 57 & 2 & 278 & 132 & 18 & 0.643 & 7 \\
\hline Kohaar & 2010 & India & Caucasian & SNaPShot & $164 / 231$ & 58 & 83 & 23 & 85 & 119 & 27 & 0.130 & 7 \\
\hline Delgodo- & 2006 & Russia & Caucasian & PCR-RFLP & $70 / 89$ & 44 & 24 & 2 & 64 & 23 & 2 & 0.969 & 8 \\
\hline \multicolumn{14}{|l|}{ Ensico } \\
\hline Hajiesmaeil & 2016 & Iran & Caucasian & PCR-RFLP & $22 / 100$ & 2 & 7 & 13 & 35 & 53 & 12 & 0.233 & 8 \\
\hline Gong & 2018 & China & Asian & TaqMan & $146 / 115$ & 26 & 64 & 56 & 85 & 27 & 3 & 0.631 & 8 \\
\hline Xie & 2016 & China & Asian & PCR-RFLP & $230 / 230$ & 106 & 63 & 61 & 136 & 53 & 41 & 0.000 & 8 \\
\hline Fan & 2014 & China & Asian & PCR-RFLP & $129 / 214$ & 68 & 53 & 8 & 148 & 63 & 3 & 0.195 & 8 \\
\hline Yang & 2011 & China & Asian & PCR-RFLP & $157 / 199$ & 89 & 67 & 1 & 132 & 54 & 13 & 0.029 & 8 \\
\hline
\end{tabular}

HWE, Hardy-Weinberg equilibrium

Table 2. Summary of meta-analysis of association of MTHFR A1298C polymorphism and cervical cancer in the whole population. 


\begin{tabular}{|c|c|c|c|c|c|c|c|c|}
\hline \multirow[t]{2}{*}{ Comparison } & \multirow[t]{2}{*}{ Studies } & \multicolumn{3}{|c|}{ Overall effect } & \multicolumn{2}{|c|}{ Heterogeneity } & \multicolumn{2}{|c|}{ Publication bias } \\
\hline & & OR $(95 \% \mathrm{CI})$ & Z-score & p-value & $I^{2}(\%)$ & $p$-value & Begg's test & Egger's test \\
\hline recessive genetic mode & 7 & $0.48(0.25,0.92)$ & 2.20 & 0.028 & 89.8 & 0.000 & 0.176 & 0.415 \\
\hline dominant genetic model & 7 & $2.91(0.93,9.12)$ & 1.83 & 0.067 & 83.1 & 0.000 & 0.881 & 0.691 \\
\hline homozygous genetic model & 7 & $3.76(0.92,15.40)$ & 1.84 & 0.066 & 86.7 & 0.000 & 0.881 & 0.536 \\
\hline heterozygous genetic model & 7 & $1.75(1.05,2.92)$ & 2.15 & 0.031 & 81.3 & 0.000 & 0.453 & 0.556 \\
\hline allelic genetic & 7 & $1.99(1.08,3.67)$ & 2.20 & 0.028 & 92.9 & 0.000 & 0.176 & 0.375 \\
\hline
\end{tabular}

OR, odds ratio; CI, confidence interval.

Table 3 Results of the association between MTHFR A1298C polymorphism and cervical cancer risk by different ethnicities.

\begin{tabular}{|c|c|c|c|c|c|c|}
\hline \multirow[t]{2}{*}{ Comparison } & \multirow[t]{2}{*}{ Studies } & \multicolumn{3}{|c|}{ Overall effect } & \multicolumn{2}{|c|}{ Heterogeneity } \\
\hline & & OR $(95 \% \mathrm{CI})$ & Z-score & p-value & $I^{2}(\%)$ & $p$-value \\
\hline \multicolumn{7}{|l|}{ Asian } \\
\hline recessive genetic mode & 4 & $0.42(0.15,1.18)$ & 1.64 & 0.101 & 93.9 & 0.000 \\
\hline dominant genetic model & 4 & $3.06(0.43,21.92)$ & 1.11 & 0.266 & 85.1 & 0.000 \\
\hline homozygous genetic model & 4 & $4.21(0.40,44.71)$ & 1,19 & 0.234 & 89.4 & 0.000 \\
\hline heterozygous genetic model & 4 & $2.04(0.94,4.43)$ & 1.80 & 0.072 & 88.6 & 0.000 \\
\hline allelic genetic & 4 & $2.09(0.79,5.52)$ & 1.49 & 0.138 & 95.4 & 0.000 \\
\hline \multicolumn{7}{|l|}{ Caucasian } \\
\hline recessive genetic mode & 3 & $0.66(0.35,1.25)$ & 1.28 & 0.200 & 55.8 & 0.104 \\
\hline dominant genetic model & 3 & $2.66(0.55,12.91)$ & 1.22 & 0.224 & 84.1 & 0.000 \\
\hline homozygous genetic model & 3 & $3.07(0.53,17.63)$ & 1.26 & 0.209 & 76.9 & 0.000 \\
\hline heterozygous genetic model & 3 & $1.18(0.83,1.70)$ & 0.92 & 0.356 & 0 & 0.453 \\
\hline allelic genetic & 3 & $1.54(0.60,3.90)$ & 1.50 & 0.133 & 85.2 & 0.001 \\
\hline
\end{tabular}

OR, odds ratio; CI, confidence interval.

Figures 


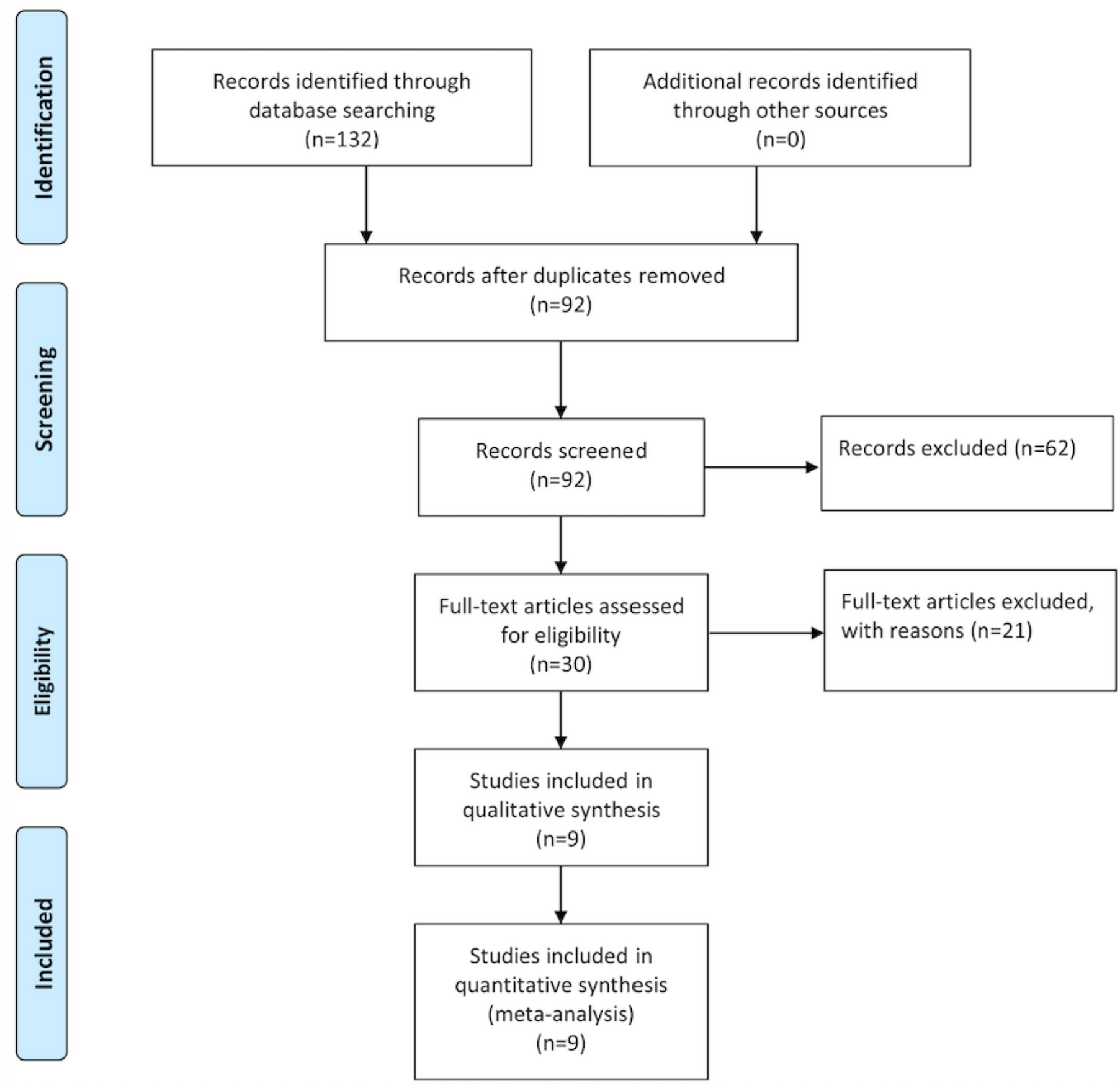

\section{Figure 1}

Flow diagram of literature screening and selection 
Study

ID

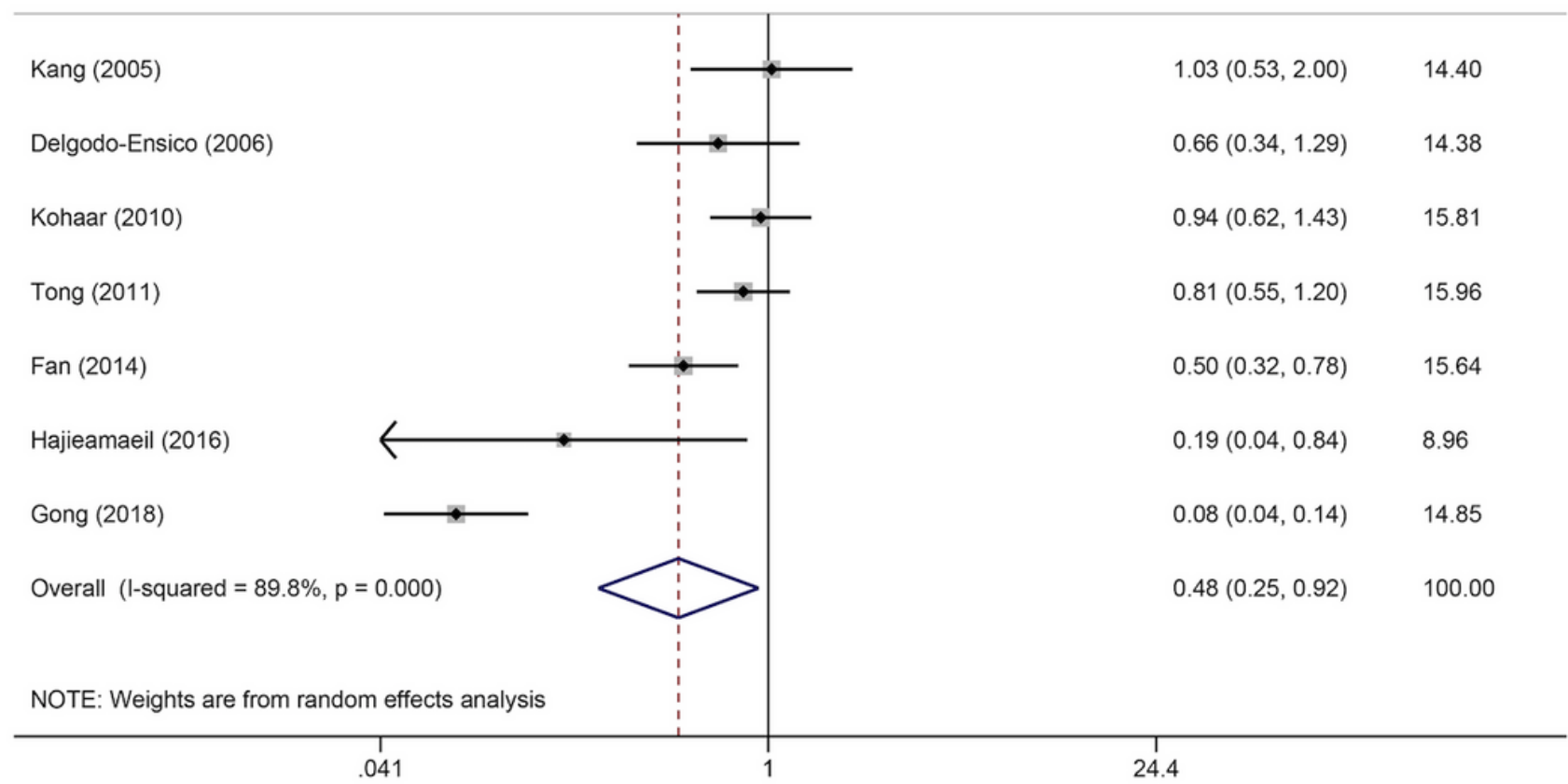

\section{Figure 2}

Forest plots for the association between MTHFR A1298C polymorphism and cervical cancer risk under recessive genetic model (AA vs. AC $+\mathrm{CC}$ ). 
ID

OR $(95 \% \mathrm{Cl})$

Weight

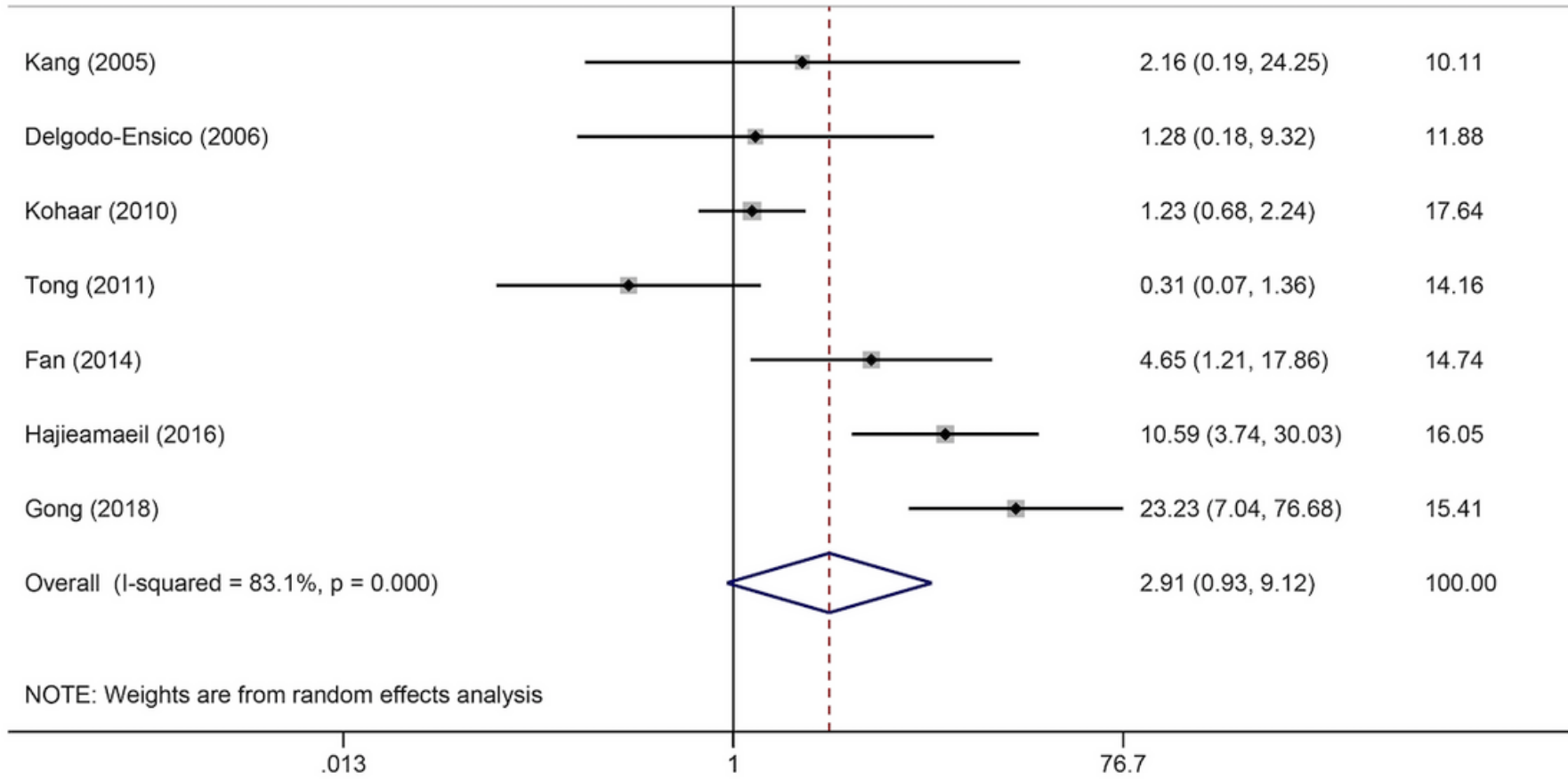

\section{Figure 3}

Forest plots for the association between MTHFR A1298C polymorphism and cervical cancer risk under dominant genetic model (CC vs. AA + AC). 


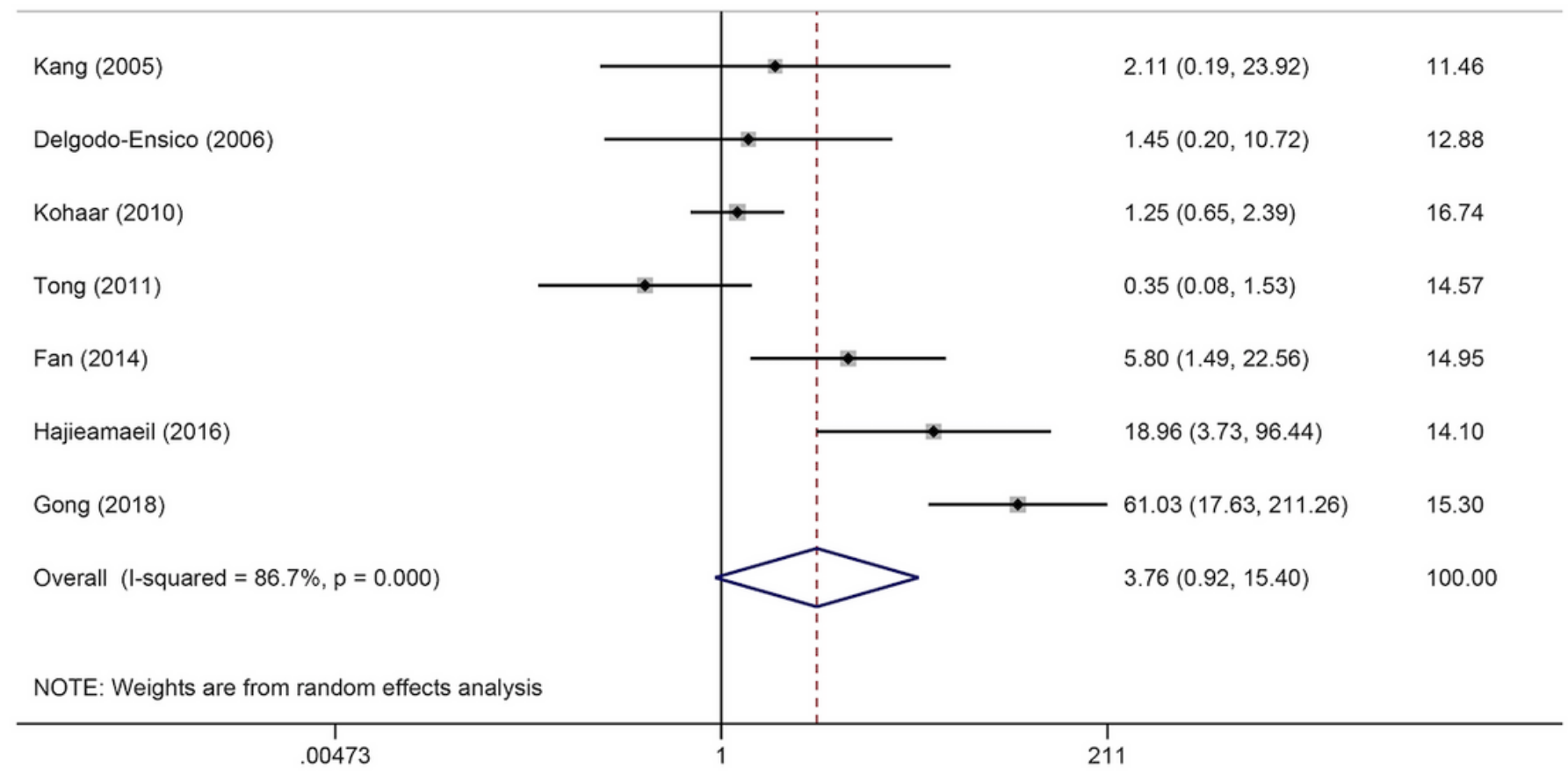

\section{Figure 4}

Forest plots for the association between MTHFR A1298C polymorphism and cervical cancer risk under homozygous model (CC vs. AA). 
ID

OR $(95 \% \mathrm{Cl})$

Weight

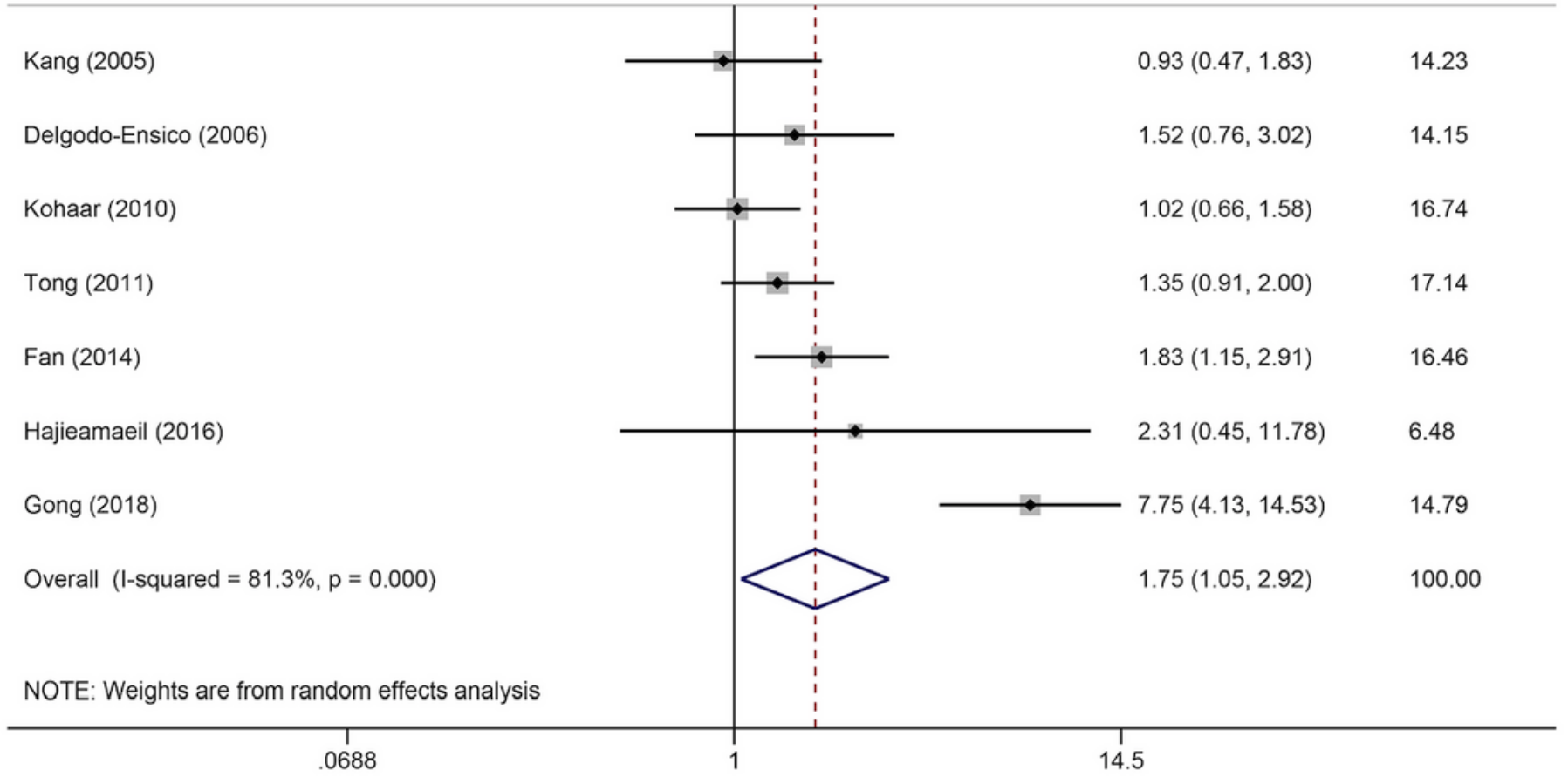

\section{Figure 5}

Forest plots for the association between MTHFR A1298C polymorphism and cervical cancer risk under heterozygous model (AC vs. AA). 


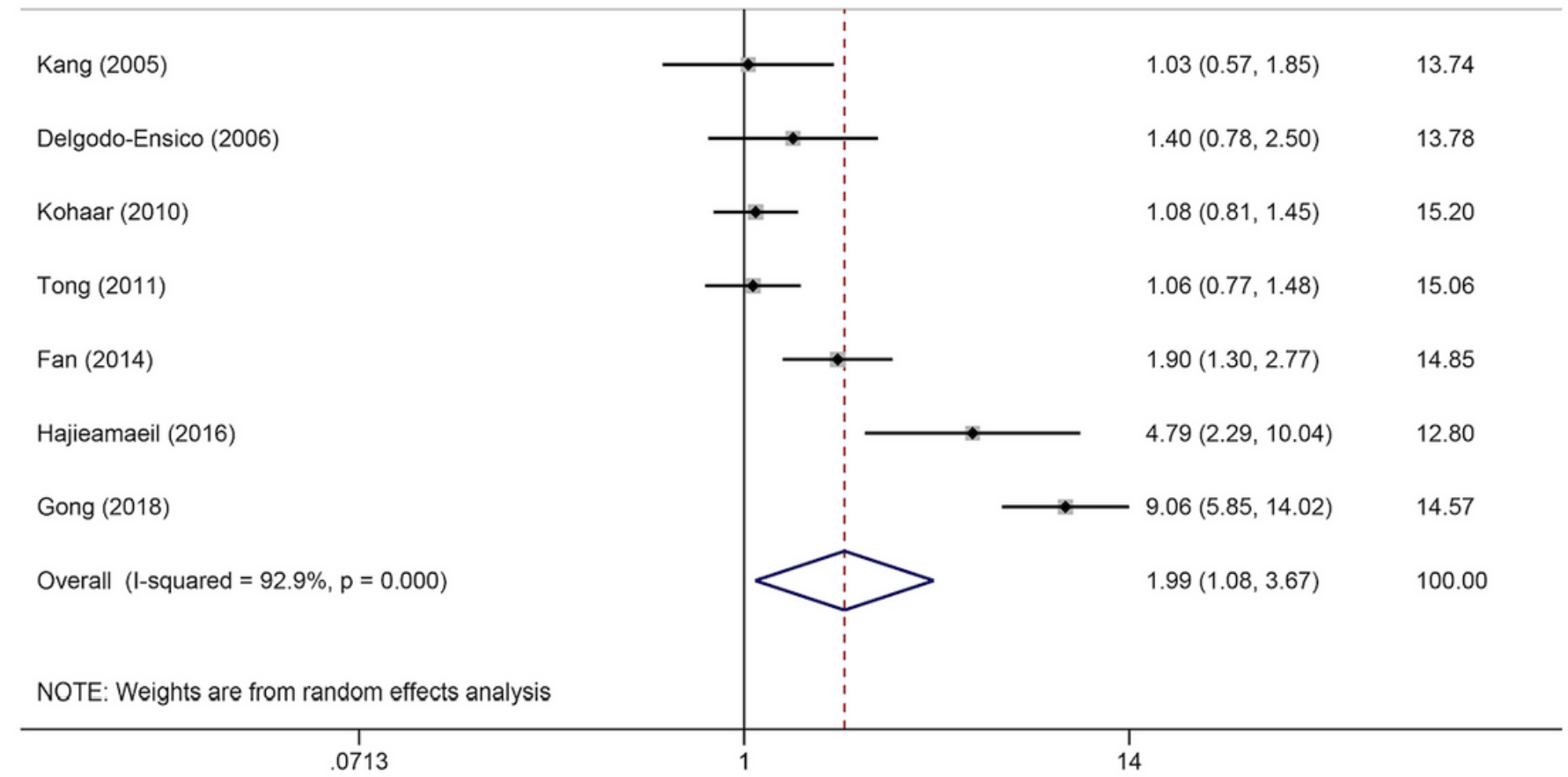

\section{Figure 6}

Forest plots for the association between MTHFR A1298C polymorphism and cervical cancer risk under allelic genetic model ( $C$ vs. $A)$. 


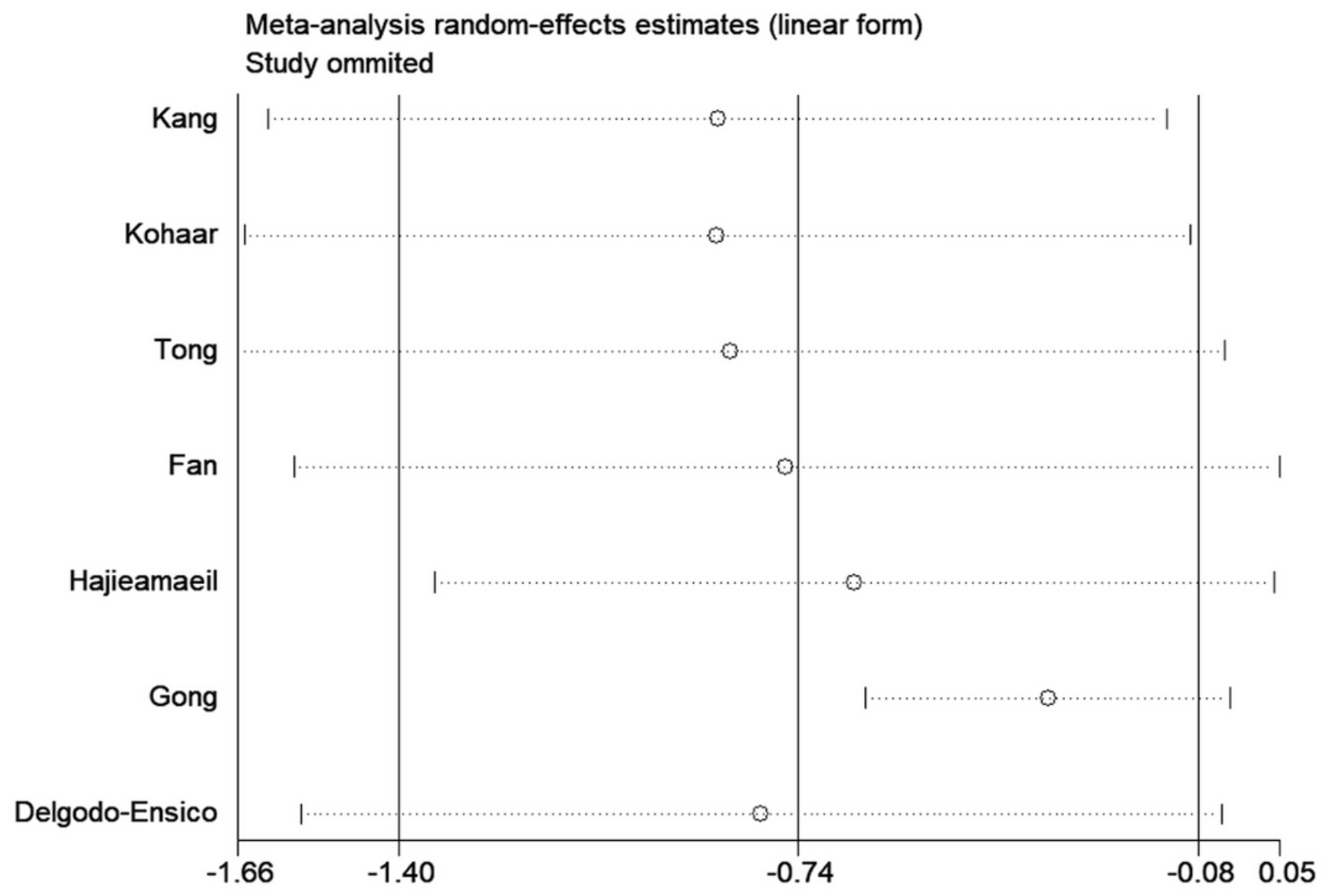

\section{Figure 7}

The sensitivity analysis results under recessive genetic model (AA vs. $A C+C C)$. 
Begg's funnel plot with pseudo $95 \%$ confidence limits

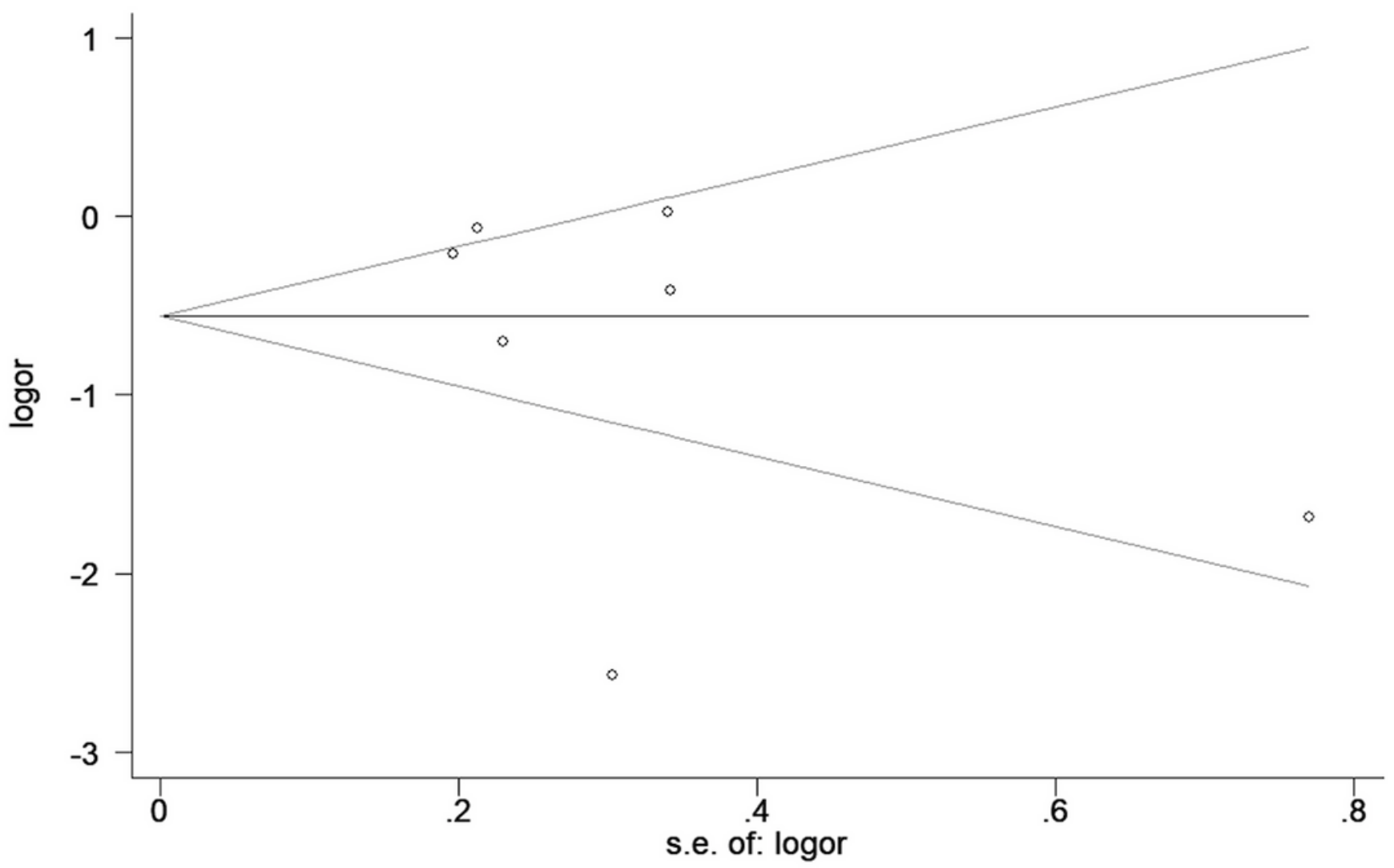

\section{Figure 8}

Funnel plots for the association between MTHFR A1298C polymorphism and cervical cancer risk under recessive genetic model (AA vs. AC $+\mathrm{CC}$ ).

\section{Supplementary Files}

This is a list of supplementary files associated with this preprint. Click to download.

- PRISMA2009Checklist20200618.doc

- PRISMA2009FlowDiagramMSWord20200618.doc 